\title{
O foco míope: apontamentos sobre o cuidado à crise em saúde mental em emergências de hospitais gerais ${ }^{1}$
}

The myopic focus: notes about the crisis in mental health care emergencies in general hospitals

El enfoque miope: notas sobre la crisis en el cuidado de emergencias de salud mental en los hospitales generales

\section{Simone Mainieri Paulon}

Universidade Federal do Rio Grande do Sul, Porto Alegre, RS, Brasil.

\section{Alice Grasiela Cardoso Rezende Chaves}

Universidade Federal do Rio Grande do Sul, Porto Alegre, RS, Brasil.

\section{André Luis Sales Leite}

Universidade Federal do Rio Grande do Sul, Porto Alegre, RS, Brasil.

\section{Cássio Streb Nogueira}

Universidade Federal do Rio Grande do Sul, Porto Alegre, RS, Brasil.

\section{Diego Drescher de Castro}

Universidade Federal do Rio Grande do Sul, Porto Alegre, RS, Brasil.

\section{Liana Cristina Della Vecchia Pereira}

Grupo Hospital Conceição, Porto Alegre, RS, Brasil.

\section{Mário Francis Petry Londero}

Univates, Lajeado, RS, Brasil.

\section{Renata Flores Trepte}

Universidade Federal do Rio Grande do Sul, Porto Alegre, RS, Brasil.

\section{Resumo}

O artigo discute a atenção à crise em saúde mental com base em uma pesquisa-intervenção em andamento que vem cartografando os modos de acolhimento operados em três emergências de hospitais gerais de Porto Alegre. Os processos de cuidado em relação à saúde mental aparecem tão plurais e individualizados quanto as estratégias de que estes trabalhadores lançam mão para dar conta das ansiedades que tais atendimentos mobilizam. Neste percurso de pesquisa no qual a dimensão de formação e intervenção não estão separadas, a proposta é de pôr em análise o acolhimento com classificação de risco junto ao tema da crise em saúde mental, na perspectiva da Política Nacional de Humanização. O medo ao desconhecido, o 
estigma associado à loucura e, fundamentalmente, a sensação de despreparo dos profissionais para escutar e resolver os problemas que surgem nos atendimentos emergenciais produz efeitos de invisibilidade sobre a dimensão da saúde mental presente em muitos desses atendimentos. Uma espécie de "foco míope" no trabalho aí desenvolvido emerge como efeito deste modo de trabalhar que, sendo tomado como analisador, pode apontar caminhos de resgate ao sentido, muitas vezes perdido, do acolhimento como diretriz e dispositivo de humanização da saúde.

Palavras-chave: Acolhimento, Classificação de Risco, Crise, Reforma Psiquiátrica, Política Nacional de Humanização.

\begin{abstract}
This paper discusses the attention to the crisis in mental health mapping the reception modes operated in three general hospitals emergencies in Porto Alegre. The writing originates from an ongoing research intervention that began its incursion into the field from researchers' observations and interviews with studied service workers, in which the processes of care in relation to mental health are already showing themselves as plural and individualized as the strategies that these workers use to manage the anxieties that such care mobilizes. In this way of research in which the dimension of training and intervention are not separated, the proposal is to put on analysis the reception with risk classification with the theme of the crisis in mental health, on a perspective guided by the National Humanization Policy of Care. The fear of the unknown, the stigma associated with madness and, fundamentally, the fact that professionals feel unprepared to listen and solve problems that arise in emergency care, produces effects of invisibility about the dimension of mental health existent in many cases. A kind of "myopic focus" on these units work emerges as an effect of this way of working which, being taken as analyzer, can point out ways to rescue the lost meaning, in many of these services, of the reception as a guideline and a device of humanization in health.
\end{abstract}

Keywords: Reception, Risk Classification, Crisis, Psychiatric Reform, National Humanization Policy.

\title{
Resumen
}

El artículo aborda la atención a la crisis en salud mental basado en una investigaciónintervención en curso que viene cartografando los modos de acogida utilizados en tres 
emergencias de hospitales generales de Porto Alegre. Los processos de atención en salud mental se presentan tan plurales y individualizados como las estratégias de las cuales echan mano los trabajadores para hacer frente a las ansiedades movilizadas por estos atendimentos. En este proceso de investigación, en el cual la dimensión de la formación y de la intervención no estan separadas, la propuesta és de poner en análisis el Acogimiento con Clasificación de Riesgo y el tema de la crisis en salud mental, desde la perspectiva de la Política Nacional de Humanización. El miedo a lo desconocido, el estigma asociado con la locura y fundamentalmente el despreparo sentido por los profesionales para escuchar y resolver los problemas que surgen en la atención a las emergências produzen efectos de invisibilidad sobre la dimensión de la salud mental presente en muchos de estos atendimientos. Una especie de "enfoque miope" en el trabajo desarrollado surge como efecto de este modo de trabajar que, al ser tomado como analizador, puede señalar caminos hacia el rescate del sentido, muchas vezes perdido, del acogimento como diretriz y dispositivo de humanización de la salud.

Palabras-clave: Acogimiento, Clasificación de Riesgo, Crisis, Reforma Psiquiátrica, Política Nacional de Humanización.

\section{Primeiras incursões emergenciais}

Este artigo apresenta

desdobramentos da pesquisa:

"Humanização em saúde mental: estratégias de acolhimento à crise em serviços de emergência de hospital geral". Essa investigação é subsidiada pela mudança no modelo de assistência no campo da saúde mental, para a qual foi necessária a criação de dispositivos de atenção diferenciados, que funcionassem em rede e que dessem conta da singularidade de cada demanda surgida em situações de adoecimento psíquico - entre elas as situações de crise - cujo modo de operar não mais estaria centrado na lógica manicomial. Dessa forma, a Lei 10.216 da Reforma Psiquiátrica (Brasil, 2001) e a portaria 2048/GM (Brasil, 2002) determinam que a atenção às urgências psiquiátricas é uma responsabilidade dos serviços de urgência e emergência dos Hospitais Gerais. $\mathrm{O}$ atendimento à crise em saúde mental passaria a ser realizado nos hospitais gerais, os quais deveriam assumir uma posição estratégica no cuidado das pessoas com transtornos psíquicos, à medida que se determina o progressivo fechamento dos hospitais psiquiátricos. 
Entretanto, é possível observar algumas problemáticas no que diz respeito ao modo e à velocidade com que a rede de saúde tem-se estruturado diante do ritmo das necessidades da população usuária e das próprias proposições jurídico-políticas criadas para atendê-la.

Diante do breve panorama aqui apresentado, temos a intenção de investigar os atuais modos de acolhimento realizados no atendimento aos usuários que apresentam crise em saúde mental ${ }^{2}$ nos serviços de emergência de três hospitais gerais na cidade de Porto Alegre/RS. A primeira etapa da pesquisa, já concluída, foi realizada no segundo semestre de 2012. Incluiu 13 entrevistas com trabalhadores e gestores que atuam nas emergências, elaboração e análise coletiva de diários de campo dos pesquisadores com observações dos processos de acolhimento realizados em cada um dos três hospitais.

As três emergências hospitalares em estudo trabalham o Acolhimento com Classificação de Risco, um dos dispositivos utilizados para organização do acesso e humanização do Sistema Único de Saúde (SUS). O acolhimento é proposto pela Política Nacional de Humanização (PNH) tanto como diretriz ético-política, quanto como dispositivo que interfere nos processos de trabalho e nos modos de se produzir saúde. Tal Política considera o acolhimento como postura ética e como tecnologia relacional de escuta, construção de vínculo, garantia do acesso com responsabilização e resolutividade dos serviços (Brasil, 2009). Um dos dispositivos associados na operacionalização do acolhimento em serviços de emergências e urgências propostos pela PNH são os protocolos de classificação de risco, entendidos como ferramenta para organizar e garantir o atendimento de todos, conforme a gravidade da situação, dividindo em eixos e áreas os cuidados em saúde nas emergências: Vermelho, Amarelo, Verde e Azul. Entretanto, essa política considera que apenas a utilização desse recurso de maneira mecânica não é suficiente, pois não contempla os "aspectos subjetivos, afetivos, sociais e culturais cuja compreensão é fundamental para uma efetiva avaliação do risco e da vulnerabilidade de cada pessoa" (Brasil, 2009, p.40). Dessa forma, o protocolo não substitui o diálogo, a interação e a escuta do cidadão e de sua queixa para a avaliação do seu potencial de agravamento, ou seja, o acolhimento não se restringe à aplicação do protocolo. Assim, um dos objetivos da pesquisa, ao identificar e analisar os atuais modos de acolhimento 
realizados junto aos usuários em sofrimento psíquico que chegam às emergências dos três hospitais gerais, consiste em subsidiar uma eventual revisão dos critérios de saúde mental constantes nos protocolos de classificação de risco desses hospitais, bem como promover uma sensibilização dos trabalhadores quanto modo de realizar a acolhida dentro desses serviços estratégicos para a consolidação de um novo modo de cuidar em saúde mental.

A partir da imersão no campo problemático tratado nesse estudo, um primeiro olhar sobre os dados até agora produzidos, permitiu elencar quatro categorias de análise, com o objetivo de sistematizar e problematizar futuras intervenções que serão realizadas na próxima etapa da pesquisa junto às equipes das emergências. As categorias de análise destacadas são: concepção de acolhimento, função da emergência, modos de trabalho e diagnóstico de crise em saúde mental.

De início, é preciso sinalizar que, com nossa experimentação do campo a partir das visitas que realizamos, percebemos a heterogeneidade do modo como os três hospitais concebem e experimentam o acolhimento dos casos de saúde mental em suas unidades. Tal constatação nos trouxe a pista de que a construção do acolhimento em cada realidade e fazer cotidiano está relacionada ao entrecruzamento de planos distintos, campo de tensão entre formas e forças que se processam e que produzem desvios à medida que os encontros de cuidado acontecem em ato. Essa experimentação nos convocou a habitar uma incômoda zona de indiscernibilidade acerca da concepção de acolhimento, produzida pela problematização do como e do quê tem sido acolhido nas práticas de cuidado em cada hospital.

A esse respeito, através da análise do protocolo utilizado por uma das unidades hospitalares, verificamos que, já em sua introdução, tal documento trata, claramente, de um processo de triagem. Em nenhum momento ao longo de suas páginas a palavra acolhimento é utilizada e em um ponto refere que a triagem serve para "classificar e escolher" (Fernandes, Ramos, Frustockl e França, s.d., p.1). O texto de introdução deste documento segue descrevendo a origem militar desse termo, utilizado em campos de batalha para escolher "quem valeria a pena salvar", de acordo com os recursos disponíveis, dentre aqueles feridos em combate: "o objetivo geral da classificação era retornar o maior número possível de soldados ao campo de batalha" (idem, p.1). Tal analogia com a 
linguagem militar, entretanto, parece transcender a origem do termo narrada nos documentos para deixar transparecer relações de cuidado que se concretizam nesses tensos espaços hospitalares. Parece que a rápida triagem feita em uma dessas emergências observadas, por exemplo, serve somente para devolver os indivíduos às batalhas de suas vidas imersas num capitalismo produtivista, servindo mais à continuidade de um funcionamento social e econômico instituído do que à proteção e cuidado da vida. Segundo uma profissional entrevistada, "no acolhimento os pacientes relatam o seu problema e a partir daí é triado de acordo com a classificação de

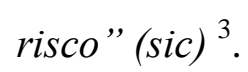

O que nos ocorre é que em meio a essa preponderância do olhar aos aspectos físicos mensuráveis, há o centramento do cuidado em um saber individualizado, que pode ser denominado tecnologia leve/dura (Merhy, 2002). Essa tecnologia consiste em saberes bem estruturados que operam no processo de trabalho em saúde, como a clínica médica, a clínica psicanalítica, a epidemiologia, o taylorismo e o fayolismo e que irão individualizar, por sua vez, um corpo também indiviso, como em uma linha de montagem. Nessa direção, trazemos a fala de uma das enfermeiras que se ocupam do acolhimento em um dos hospitais, quando ela compara o trabalho no acolhimento ao filme de Chaplin "Tempos Modernos", lembrando especificamente da cena em que o personagem de Carlitos, de tanto apertar parafusos, sai repetindo os movimentos desconexos rua afora. Em seguida, ela acrescenta que a sua próxima escala de acolhimento ocorrerá dali a dois meses e sente-se aliviada por isso, pois prefere ficar nas máquinas de raios- $\mathrm{X}$ do que ficar ali, na linha de frente. Qual o sentido dessa recusa da funcionária em realizar práticas de acolhimento e desse desejo de estar entre máquinas ao invés de pessoas?

Neves e Heckert (2010), analisando as delicadas questões que o acolhimento mobiliza nos serviços de saúde e grupos de trabalhadores, afirmam que o trabalho deve ser compreendido como uma atividade de gestão de variabilidades e imprevisibilidades. Nessa perspectiva, ele não só é retirado do campo da repetição incessante e rotineira de prescrições externas ao processo em que é efetuado, como também deixa de estar submisso a um estado de coisas instituído. Talvez o comentário da enfermeira revele um querer colocar as coisas em seus "devidos lugares", uma vez que o trabalho com a maquinaria requer, mais apropriadamente, o tipo de conduta que lhe parece ser 
exigida para atuar nos acolhimentos da emergência. Além disso, as máquinas de raio-X não precisam ser esvaziadas de subjetividade, do conteúdo psicossocial que insiste em ser sugado das "pessoasparafuso" da linha de montagem do acolhimento/triagem. As autoras também chamam a atenção para o fato de que:

Os processos de acolhimento assim operacionalizados têm produzido, na maior parte das vezes, efeitos deletérios e de desgaste nas relações entre usuários e trabalhadores no cotidiano das práticas de produção de saúde. Isto pode ser percebido seja quando o acolhimento é vivenciado pelo usuário como mais um dique a transpor para 'resolver' suas necessidades de saúde, ou mesmo usufruir do consumo de sua dose procedimental, seja quando é visto como castigo pelos trabalhadores que são designados para a triagem, validação e/ou contenção destas necessidades. Este processo nos leva a indagar: o que se quer acolher nos processos de produção de saúde? (Neves e Heckert, 2010, p.154).

Essa indagação coloca-nos uma provocação para pensarmos sobre os modos de cuidados instituídos nas emergências. Usuários instigados a fazer malabarismos para conseguirem passar para a próxima etapa, a de póstriagem/acolhimento, trabalhadores considerando essa primeira aproximação - a produção de vínculo junto ao usuário como castigo. O que sobra desta relação que possui um caráter de obrigação? O que está contido nessa prática de cuidado que se passa na emergência que restringe ao máximo um processo de vinculação entre o par usuário/equipe de cuidadores? O que se quer e pode, de fato, acolher nos processos de produção de saúde de um serviço de emergência hospitalar?

\section{Salvar 'vidas' ou curar feridas? O tempo, o invisível e o julgamento.}

Nas emergências, é possível observar-se uma pressão por conter qualquer ato que possa trazer risco, parece sempre necessária a agilidade para anestesiar um futuro imprevisível, de maneira a não caotizar o cuidado em saúde. A Resolução do Conselho Federal de Medicina nº 1451/95 (São Paulo, 1995) estabelece nos Parágrafos I e II do Artigo I as definições para os conceitos de urgência e emergência, a serem adotas na linguagem médica no Brasil. No artigo $1^{\circ}$ define-se, ainda no parágrafo primeiro, que urgência é a "ocorrência imprevista de agravo à saúde com ou sem risco potencial de vida, cujo portador necessita de assistência médica imediata". No parágrafo segundo, a definição de emergência aparece como "a 
constatação médica de condições de agravo à saúde que impliquem em risco iminente de vida ou sofrimento intenso, exigindo, portanto, tratamento médico imediato". Assim, o emergencial está relacionado a algo que ocorre subitamente e o urgente com aquilo que tem premência. Se compararmos essas duas modalidades, é necessário demarcar que a emergência clama por uma intervenção mais rápida do que a urgência. Este risco tão eminente ao qual está exposto o corpo faz com que outros aspectos não menos importantes sejam deixados de lado. Isto é, a própria produção de vínculo, que entendemos primordial para o cuidado em saúde - seja qual for a sua especificidade - e, sobretudo, em saúde mental.

O que prevalece, assim, é um cuidado predominantemente vertical, de procedimentos biomédicos, para com um usuário submisso e em estado de passividade: uma perfeita apresentação do clássico "paciente". Cunha (2007, p. 28) aponta que "o hospital é um espaço extremamente adequado aos instrumentos da biomedicina, que cartesianamente separa a alma do corpo fatiado em pedaços estanques nas respectivas especialidades. A gravidade da questão orgânica permite que o aspecto biológico se destaque em serviços de emergência, o que fornece uma sensação de suficiência para o saber biomédico, voltado para procedimentos técnicos" com pouca exigência de diálogo com usuários e outros profissionais envolvidos. A possibilidade de morte exige pressa, como um dos trabalhadores comenta: "A nossa proposta de acolhimento é um acolhimento rápido, ele tem que ser rápido e efetivo. Porque às vezes o paciente chega pra mim e eu tenho que conseguir classificar ele rápido, justamente pra ele ter um atendimento mais rápido" (sic).

Uma constante no discurso dos profissionais das emergências são as palavras: rápido, efetivo e estabilizado. A função da emergência, segundo os entrevistados, seria devolver a estabilidade das funções orgânicas ao corpo que está sendo assistido. Por alguma razão a homeostase corporal foi rompida e isso deve ser reestabelecido de maneira efetiva. E todos os procedimentos precisam ser feitos rapidamente, pois, a depender da gravidade do dano instalado naquele organismo, esse desequilíbrio poderá levar à morte.

A partir dessa lógica, temos uma problemática em relação ao acolhimento, pois ele corre o risco de ser tomado por um viés organicista, no qual se abriria mão de entender os aspectos psíquicos e sociais 
constitutivos da vida e fornecedores de dados importantes para o cuidado em saúde. Nesse sentido, problematizar o cuidado à crise em saúde mental não significa abrir mão do atendimento de paradas cardíacas, fraturas e outras decorrências corriqueiras nas emergências, mas, sim, produzir tensão na lógica vigente de atendimento emergencial, na qual um saber biomédico focado num corpo/órgão "em falência" (ou em vias de) parece ser único, exclusivo e determinante do que merece ou não receber cuidado.

O tempo da emergência parece estar voltado para um modo de atenção que não permite espaço para o encontro palavra-chave quando se trata de entender o acolhimento em sua dimensão de diretriz da humanização da atenção na saúde. Nesta perspectiva de que o que demanda a ação rápida é sempre e apenas um corpo físico em colapso, o diálogo construtivo entre cuidadores e usuários torna-se empobrecido, com o contato restrito ao que está prescrito nos protocolos de atendimento e procedimentos a serem realizados. A lógica de atenção em saúde nas emergências daí decorrente estaria pautada pelo que Merhy (2002) descreve como "trabalho morto", isto é, por um cuidado que não está em movimento - em relação. Um dos trabalhadores entrevistados faz esta curiosa analogia: “ $O$ funcionamento da emergência é uma coisa mais Mc Donald's: não tem entrada, primeiro prato, segundo prato, terceiro prato. Eles querem ver quem é que tem risco, que tenha que internar, senão, olham o que precisa e 'deu'. A emergência é voltada para o foco da doença, ela focaliza no tratamento que estanque aquele sofrimento emergente." (sic)

Nessas circunstâncias, a rapidez no atendimento é priorizada como característica essencial do atendimento nos serviços observados. O objetivo é conseguir num menor tempo possível reunir informações suficientes pra determinar a acuidade dos casos, visando comunicar à equipe clínica qual paciente pode esperar e qual deve ser atendido imediatamente. Uma ambição muito grande que implica necessariamente um processo de simplificação, explicitado por Lipsky (2010), no qual o trabalhador tenta adequar a demanda trazida pelo usuário àquilo de que o serviço dispõe, para poder lidar com ela e salvaguardar algum sucesso no resultado do trabalho. Esvazia-se o processo, isolam-se as angústias e a complexidade do atendimento da pessoa que demanda cuidados, adequando-a ao que o hospital pode fornecer. "Olham $o$ que precisa e 'deu'!’. (sic) 
Os protocolos de classificação de risco que guiam o trabalho na emergência podem ser vistos, em última instância, como modos de otimizar tempo e recursos materiais, racionando os custos do atendimento e aumentando o foco nas informações relevantes para a decisão clínica - sinais vitais, frequência e intensidade da apresentação dos sintomas (Mackaway, Marsden \& Windle, 2006). Todo o maquinário está azeitado para que as respostas sejam as mais adequadas e eficientes possíveis, dentro de um tempo mínimo. Esse acolhimento construído por certos "saberes bem definidos" (Merhy, 2002, p. 95) expressa todo um modo de cuidado duro, "trabalho morto" sem possibilidades de trocas e de movimentos inventivos na atenção em saúde.

Contudo, retomando a intenção da $\mathrm{PNH}$, ao propor o acolhimento associado ao dispositivo da classificação de risco para humanizar o cuidado nas emergências, cabe questionar: quais são os percursos dessa proposta do acolhimento? Quando nos deparamos com práticas de cuidado nas quais um uso técnicoburocrático do dispositivo parece predominante, o "acolhimento" não estaria operando antes como modo de afastar os cuidadores dos usuários, do que como um dispositivo a favor das relações vinculares?

\section{Dos muitos mundos e modos de}

"acolher".

A crise em saúde mental pode ser considerada um episódio de desestabilização específica em que o sujeito apresenta comportamentos variáveis que parecem não dar conta das intensidades afetivas que lhe perpassam naquele momento, impedindo tanto a própria pessoa quanto aqueles de seu convívio de levarem sua vida cotidiana. Assim definida, a crise em saúde mental foi apropriada e caracterizada pelo saber médico psiquiátrico como sendo o ponto máximo de intensificação da periculosidade do sujeito, no qual ocorre aumento da imprevisibilidade das atitudes e exacerbação da presença de comportamentos bizarros. Para este saber biomédico psiquiátrico, seria o ápice da desrazão, da incapacidade e da inabilidade daquele que experimenta a crise e a cisão completa entre um momento de desorganização e todo o contexto de vida daquele sujeito (Ferigato, Campos \& Baillarin, 2007).

A esse respeito, a periculosidade vinculada à desrazão servirá para justificar a íntima conexão que o saber médico estabelecerá, na idade moderna, com o saber psiquiátrico para sustentar, a partir 
de então "cientificamente", toda uma série de comportamentos de exclusão e tratamentos morais. Como uma espécie de profecia auto-realizável, trata-se, como analisa Foucault (2010, p.18), de "mostrar como o indivíduo já se parecia com seu crime antes mesmo de o ter cometido." Por isto, ao dedicar seu célebre curso de 1975 a dissecar os laudos psiquiátricos para chegar à maneira pela qual a sociedade constitui "Os Anormais" dos quais passa a ter que se defender, Foucault está, a um só tempo, evidenciando a construção deste personagem e indicando o complexo jogo institucional em que tal modo de subjetivação é forjado. Como sintetiza o próprio autor ao finalizar a primeira aula do curso:

\begin{abstract}
Essa emergência do poder de normalização, a maneira como ele se formou, a maneira como se instalou, sem jamais se apoiar em uma só instituição, mas pelo jogo que conseguiu estabelecer entre diferentes instituições, estendeu sua soberania em nossa sociedade - é o que eu gostaria de estudar. (Foucault, 2010, p.23)
\end{abstract}

Nesses termos, um indivíduo fora de si, sem controle, apresentando risco para si e para aqueles que estão ao seu redor - corporificação do louco perigoso e assustador - é a alusão mais comum à crise em saúde mental não apenas nestes espaços de sofrimento limite de que vimos nos ocupando. Enquanto personagens desse imaginário social, os profissionais de saúde que atuam no hospital também o compõem, subjetivam-se como trabalhadores constituídos e constituintes do mesmo poder normalizador. A partir dele, operam práticas de cuidados, definem diagnósticos, classificam riscos, caracterizam as necessidades daqueles que chegam aos hospitais. Como no cinema mudo, quando o que importa é "apertar os parafusos" para a máquina continuar rodando, tais processos de trabalho tendem a gerar atendimentos "serviço-centrados" que servem para amortecer o caos que vivemos nas grandes cidades, em meio a acidentes e outras violências. Voltado para processos individuais, em detrimento de processos sociais de responsabilização e co-gestão dos processos de saúde-doença, essa modalidade de atendimento visa colocar os corpos "de volta aos seus lugares", sem pausas para problematizar a organização social ou para refletir sobre os motivos que os leva até ali.

Se o foco da atenção está direcionado aos sinais vitais e à sintomatologia física presente no quadro clínico em nome de uma agilidade e eficiência no atendimento, qual será o espaço reservado para tudo o que não 
estiver inscrito nesse script? O que sobra do sujeito-usuário que chega com sofrimentos difusos, numa emergência? Que acontece quando o tipo de dor e sofrimento que "urge" num usuário é de outra ordem que não aquela que costuma estar no foco desses serviços? Estamos aqui problematizando o fato de que, caso o que se apresente no momento do atendimento não for, necessariamente, da ordem da sintomatologia usual dos parâmetros da clínica biomédica, o atendimento é rapidamente entendido como alheio à emergência.

Diante disso, quando pensamos o cuidado na perspectiva da humanização em saúde, mais especificamente, ao dialogarmos com a Política de Saúde Mental à luz dos princípios e diretrizes da $\mathrm{PNH}$, temos a impressão de que a organização das emergências, pautada nesse cotidiano protocolar focado em procedimentos técnicos para corpos biológicos, produz uma espécie de "foco míope", distorcido em relação aos sofrimentos complexos que se apresentam a cada dia. Nesse caso, o que é preocupante são os efeitos que tal organização acarreta para a atenção prestada ao usuário com problemas em saúde mental em crise que adentra nesses serviços.
Poderíamos demarcar que, tanto nas entrevistas quanto nas observações aos modos de acolher, toda essa estrutura hospitalar e lógica biologicista que a sustenta produz um efeito de invisibilidade para as demandas de crises em saúde mental. Quando perguntados sobre o atendimento a esse tipo de situação na emergência, os entrevistados, em princípio, mencionavam que não era algo significativamente presente em seus cotidianos. As situações de atendimento à crise em saúde mental "sumiam" diante dos inúmeros procedimentos diários voltados para os corpos dos indivíduos que chegam em situações-limite de risco, dor e sofrimento. Contudo, ao insistirmos um pouco mais no tema, muitos casos eram lembrados, como, por exemplo: atendimentos às pessoas que tentaram suicídio, desintoxicação para usuários de drogas, crises depressivas, doenças crônicas que progressivamente desgastam as relações e debilitam emocionalmente usuários e familiares, etc.

A explicação da "escassa demanda" em relação à saúde mental, feita por um dos entrevistados, nos permite explorar com mais precisão os efeitos produtores de invisibilidade oriundos da combinação "foco na sintomatologia"-“necessidade de eficiência para evitar a morte daquele que 
chega": "A gente atende muito pouco paciente aqui com a queixa da saúde mental. A gente, normalmente, atende o paciente que tem o problema de saúde mental, mas ele vem com uma queixa clínica. Ou é o paciente asmático, ou o paciente que tá com dor, tá com pneumonia, tá com algum problema clínico. Então, normalmente, a gente atende esse paciente, nesta situação” (sic).

\section{Do que (se) pode esperar (ou não) na emergência.}

Nessa invisibilidade da crise e do sofrimento em saúde mental é interessante observar a fala de mais um entrevistado perguntado sobre a classificação de risco: "não tem classificação de risco específico pra isso (saúde mental) porque não é o perfil do hospital. Ele vem ali pra fazer a classificação de risco, é um paciente que obrigatoriamente tem que ter passado por trauma, ou ser um paciente que tenha tido um atendimento cirúrgico, neuro-cirúrgico ou de traumato-ortopedia, tudo relacionado ao trauma, com exceção da neurocirurgia que pode ser um acidente vascular cerebral ou não. Então aqui não tem esse atendimento ao paciente psiquiátrico" (sic).

Ao vincular o atendimento da emergência, direta e necessariamente, à presença de sintomas físicos e, neste caso, sintomas físicos no limite de risco que demande a intervenção emergencial, assume-se, concomitantemente, uma concepção de doença e, por consequência, uma posição tecno-política quanto aos modos de trabalhar em saúde. O funcionar da emergência, no seu tempo acelerado e peculiar de "girar as engrenagens", facilmente reproduz uma lógica ligada a uma concepção restrita de saúde enquanto ausência de sintomas orgânicos. A porta de entrada da emergência funciona como uma espécie de grosseiro funil, no qual a partir de fatores pretensamente objetivos e normativos classifica-se aqueles usuários que são de fato uma emergência daqueles que podem esperar.

Apesar da dupla possibilidade de interpretação da palavra trauma, o modo como é utilizada nas Emergências dissociando uma dimensão física de outra psicológica do evento traumático - aponta para uma escolha cartesiana e geralmente encoberta por juízos morais que facilita a decisão de dar prioridade no atendimento às "feridas expostas", aos riscos mensuráveis e visíveis. Tais leituras diagnósticas, por consequência, reforçam o lócus de poder ocupado pelo saber biomédico e atualizam a centralidade da 
organização hospitalar como melhores, quando não únicas, formas de cuidado efetivas. Um dos efeitos problemáticos gerados por esta cultura hospitalocêntrica é a conhecida hiperlotação das Emergências, já que enquanto não se depararem com um "jaleco branco" e, de preferência, saírem medicados de um atendimento, os usuários parecem não se sentir de fato acolhidos em suas demandas de "saúde".

Outro efeito, que aqui nos interessa especialmente explorar, diz respeito a um movimento de negação, observado no campo de pesquisa, como estratégia elementar de evitação. O trauma que transcende corpo e mente e que é produzido na subjetividade que abrange e não separa o mental do corporal parece não ter emergência, fica invisível e pode esperar e ser vagarosamente silenciado!

Além dessa invisibilidade do sofrimento em saúde mental, ainda há outra característica dos acolhimentos em emergência que atravessam o cuidado ali ofertado, no caso, uma concepção moral do cuidado. O julgamento moral está presente desde a triagem, a qual culmina em uma classificação de risco que mescla a objetividade de protocolos organicistas com um olhar moralizante da situação que se encontra o usuário que chega para atendimento, o que acaba relegando a saúde mental a um segundo plano e fazendo seleções a partir de determinados parâmetros, como:

[...] a comunhão de preconceitos e valores sociais no descaso ao atendimento de pacientes categorizados como "essencialmente não urgentes" (os alcoólatras, drogados e pacientes psiquiátricos), a presteza maior no atendimento a usuários de classe social e nível cultural mais abastados, a importância da identificação dos que fingem ou estão dizendo a verdade sobre suas urgências e no consenso de que se a dor ou o problema é antigo, quem esperou tanto para acessar o serviço pode esperar mais. (Neves, 2006, p.692)

Em consonância com a autora está a fala de uma trabalhadora da emergência ao comentar sobre a experiência de atender aos alcoolistas: "Esses sim, esse nós da equipe de enfermagem temos bastantes dificuldades de lidar, porque tu vê o vício como algo que a pessoa vai e faz por que quer, tem livre arbítrio, ele escolheu o vício. Até as primeiras idas, até antes da dependência" (sic). Não é difícil supor que a este tipo de avaliação moral expressa com a naturalidade de quem quer fazer bem o seu trabalho de "cuidar de quem realmente quer ser cuidado", correspondem práticas clínicas, ofertadas 
muitas vezes de maneira compulsória por alguns trabalhadores de saúde, que envolvem descasos, incapacidade de escuta ou até negligência para com sujeitos em crise de abstinência ou em estado de torpor. Nesse sentido, subjugar um cidadão que chega à emergência com algum tipo de sofrimento psíquico limite, reduzindo-o a um lugar de pecado, de vergonha pelos seus atos fora dos padrões aceitos socialmente, parece ser efeito de um poder de normalização que, como assinala Foucault (2010), emerge da junção das lógicas médica e judiciária, efetuada pela ativação de categorias elementares da moralidade, de um discurso essencialmente parental-infantil, que é o discurso dos cuidadores quando se imbuem do saber absoluto sobre "o que é bom para o outro".

A dificuldade no atendimento a um alcoolista, por exemplo, passa pela quebra de parâmetros que tal usuário apresenta para a equipe de saúde, que agora, ao invés de consertar uma fratura, necessitará acolher demandas subjetivas (leia-se, nessa lógica, aquelas que poderiam esperar, que tomam o lugar das "realmente emergentes”). Isso quando não apenas respondem à demanda física do problema do alcoolista e o mandam para casa. A produção de um cuidado que passe pelo entendimento biopsicossocial e que inclua dimensões afetivas nos encontros parece ser necessária, mesmo que encontremos muitas angústias para dar conta dessas especificidades. Ainda que invisíveis, elas se encontram em qualquer serviço de saúde e demandam sempre um acolhimento integral, bem mais complexo do que aquilo que as etiquetas coloridas dão conta de indicar. A invisibilidade torna a prática do cuidado deveras incerta, sem medidas exatas que coloquem o cuidador numa zona de controle da situação. Os resultados concretos e objetivos do cuidado ficam enfumaçados, se instala um "não saber e um não ter garantias de cura que muitas vezes é desorganizador para a identidade de uma equipe de saúde de emergência que se constitui sob a égide médica de ser supostamente aquele que sabe" (Luccia e Luccia, 2012, p.571).

Quando uma criança chega à emergência por automutilação, ou mesmo quando um adulto adentra a sala com os pulsos cortados, os profissionais entendem que sua função nesse caso é de limpar e suturar os ferimentos. $O$ motivo da consulta é o ferimento - novamente o físico - e os possíveis procedimentos que nele possam ser executados. Já os motivos do plano psíquico e social que possivelmente causaram tal emergência (e não raras vezes causarão novamente e justificarão uma 
reinternação - uma das variáveis determinantes da hiperlotação das emergências) não são alvo de investimentos por parte das equipes. Sterian (2000) comenta sobre a questão do suicídio e a importância de um socorro que atenda o sujeito como um todo quando ele chega até as emergências:

Muitas vezes, nós só podemos ter acesso ao paciente no instante de irrupção da crise em diante. As tentativas de suicídio são os eventos que melhor exemplificam este fato. São os de maior incidência entre os atendimentos que se iniciam em hospitais gerais e, depois demandam atenção psicológica. Eles nos lembram, também, que as emergências psíquicas podem implicar o corpo e vice-versa. (Sterian, 2000, p. 13)

Nesse sentido, apontamos para o risco do descuido produzido por uma espécie de foco míope que guia o trabalho na emergência, pois junto com as ponderações da autora acima citada, podemos tensionar esse assunto a partir de mais uma fala de um trabalhador da emergência: "a tentativa de suicídio por cortes nos pulsos ou intoxicação medicamentosa é o que mais aparece" (sic). Na realidade, é só isso que aparece, no caso, o ato em si da tentativa de suicídio, a ação de cortar-se ou de tomar uma medicação, sendo completamente obscurecida qualquer questão referente ao tipo de sofrimento psíquico que a justificou. Nessa perspectiva de cuidado que limita o entendimento do trabalho em emergência a uma sutura - ao retorno da homeostase daquele organismo - se perde de vista a expressão de um sofrimento e a necessidade de que algum plano de cuidado seja traçado para dar conta disso.

Há de se pensar sobre o porquê disso e, mais uma vez, as entrevistas nos sinalizam uma direção ao apontar que " $o s$ profissionais sentem medo de cuidar daquilo que desconhecem, do que não foram capacitados" (sic). Tais trabalhadores realizam procedimentos complexos em tempo mínimo, como lhes é exigido na emergência, e, no entanto, quando lhes é demandada uma desaceleração para conversa e escuta, acabam sentindo-se imobilizados e sem capacidade técnica para fazê-lo. Este movimento de escuta um pouco mais livre, mais solta, no qual o ato de cuidado se produz a partir da relação é uma prática que parece não caber em um espaço onde todas as ações estão voltadas para manejar, com o máximo de agilidade, gritos, desespero, doenças emergentes e muita correria.

Alguns estudos recentes apontam 
que, apesar do atendimento às emergências requerer um treinamento específico e uma agilidade assertiva e muito específica, esse tipo de atendimento corresponde a um percentual muito pequeno, de cerca de $5 \%$ da demanda diária de um pronto-socorro. E ainda assim, curiosamente, os profissionais costumam sentir-se despreparados para escutar e resolver os problemas que surgem nos atendimentos emergenciais não característicos ao costume instalado nesse serviço que se apresentam, tornando-se menos disponíveis a acolher de fato $o$ usuário em sua complexidade (Ribeiro \& Castro, 2012).

O desconhecimento sobre como agir, a falta de capacidade técnica para manejar o caso e a ausência de condutas nos protocolos para lidar com as questões do campo da saúde mental percorre o imaginário dos trabalhadores, colocandoos numa posição de angústia frente ao atendimento de usuários em sofrimento psíquico. Jardim e Dimenstein (2007) trabalham a questão da crise em saúde mental nas emergências comentando 0 quanto os profissionais são acometidos por um tal incômodo ao se depararem com a demanda do acolhimento de tais casos, ratificando ou mesmo provocando a ideia da invisibilidade no atendimento de saúde mental:
O foco do trabalho das urgências psiquiátricas está primordialmente no procedimento, em sua dimensão biológica, no corpo pensado como objeto de intervenção da anatomia patológica e qualquer fator que extrapole esse âmbito é desconsiderado. Então, até mesmo enquanto doença mental, a loucura foge da lógica das urgências. Não se manifesta enquanto lesão palpável ou visível, [ela] evoca outros questionamentos, incomoda por diferir tanto das outras demandas, não se encaixa no espaço, não se submete à autoridade, põe em xeque os técnicos e seus sábios conhecimentos, desvela as suas impotências. (Jardim e Dimenstein, 2007, p. 182).

O mal-estar da impotência instalada pelo adoecer psíquico que chega até as emergências é histórico, remete a uma área da medicina que, muitas vezes, sofre questionamentos enquanto saber científico, justamente, por não ser palpável e assimilável em termos de procedimentos técnicos que dariam conta da intervenção. A psiquiatria com seus recursos diagnósticos e medicamentosos ainda não estanca o sofrimento psíquico, o que como já comentado, tensiona um lugar de suposto saber atribuído à medicina em geral, sobretudo, em seu maior reduto - o hospital. Nesses casos, ao contrário dos procedimentos já protocolados e por isso mesmo duros, são requeridos atendimentos 
menos complexos em termos de conhecimento científico/padronizados ou mesmo de aparelhos tecnológicos, isto é, se faz necessário o uso de técnicas de cuidado que envolvam uma abertura para o estar com, o conversar com o outro que se está em relação: - "Fale com ela"4! É um "trabalho vivo, em ato", como nos indica Merhy (2002), voltado para o impensável que se desenvolve na medida em que se vai acolhendo a relação de cuidado que está por se fazer, sem mediações protocolares que apontam cada procedimento.

Entretanto, a referida redução da complexidade da experiência de crise a um conjunto de sinais e sintomas pertencentes ao campo da nosografia psiquiátrica é aquilo que produz o foco norteador das terapêuticas prescritas para o tratamento emergencial em saúde mental. Mais uma vez, apontamos para a miopia deste foco, posto que tornar invisível ou somente medicalizar o mal estar a tal ponto de anestesiá-lo é apenas suprimir as repercussões do sofrimento no sujeito. Assim, não será o sujeito em sua necessidade de suporte e apoio o alvo do tratamento. A meta da emergência é intervir na crise e controlá-la a fim de estabilizar os usuários gravemente doentes e garantir a sua segurança e das outras pessoas (Fortes, 2010, p. 327). Como vimos, as condutas terapêuticas terão a prática do controle do risco como foco e se darão pela via da contenção - física, química ou moral - e da tutela na tentativa de retomar a estabilidade anterior ao momento de deflagração da crise (Ferigato, Campos \& Baillarin, 2007).

\section{Para não fechar, mas fazer circular o sintoma...}

Com essa problemática da invisibilidade e do foco míope no atendimento à crise em saúde mental nas emergências, algumas questões circulam no pensamento dos pesquisadores: o que está instituído no cuidado de emergência? Quais procedimentos são permitidos e que tempo é esse ali processado? Rilke (2008, p. 10) descreve um pouco esse processo instituído nos hospitais que serve como parâmetro para pensarmos as emergências:

\footnotetext{
Esse excelente Hotel é muito antigo. Já nos tempos do Rei Clodovico se morria nele em algumas camas. Hoje, morre-se em 559 leitos. Produção em série, naturalmente. E numa produção dessas não se executa tão bem a morte individual, mas também isso é coisa que pouco importa. O que interessa é a quantidade. Quem, hoje, dá valor a uma morte bem executada? Até os ricos, que poderiam dar-se o luxo de morrer bem, começam a se mostrar relaxados,
} 
indiferentes; faz-se cada vez mais raro o desejo de ter uma morte particular. Mais um pouco, e será tão raro quanto ter uma vida particular. Meu deus: tudo isso está aí. A gente chega, encontra a vida pronta, basta vesti-la [...] E morre-se como o acaso determinar; morre-se a morte que faz parte da doença (pois, desde que conhecemos todas as enfermidades, também sabemos que os diferentes fins pertencem às doenças, não às pessoas; e o doente, na verdade, nada tem a dizer).

O poeta e literato escreve sobre a desnaturalização da morte particular, da desvinculação de sentido entre o homem e sua falência em vida, porém, é possível remeter tal problemática de Rilke ao processo de cuidado cotidiano das emergências, nos quais pouco se tem espaço para uma escuta do padecimento singular do sujeito. Em consonância com o que $o$ autor bem escreve, um dos entrevistados da pesquisa dispara - "o que interessa é a quantidade" (sic) - o volume dos casos atendidos e as doenças solucionadas completamente desvinculadas do sujeito que sofre a dor.

Além disso, como comentam Lancetti e Amarante (2006):

Os profissionais de saúde são capacitados para diagnosticar e propor uma terapêutica. Exemplo: uma pessoa tem infecção urinária, toma antibióticos durante sete dias, depois realiza exame, o caso "fecha". Nos casos de saúde mental, quando um paciente de uma família melhora, outro descompensa, os casos nunca "fecham". O sintoma não se elimina, o sintoma circula. (Lancetti \& Amarante, 2006, p. 632).

O ritmo frenético, observado pelos pesquisadores e descrito pelos trabalhadores, que se impõe aos profissionais na emergência, dificulta a escuta, em alguns casos, até mesmo impede que ela aconteça. Mas, o que estaria impedido de ser acolhido quando se instituiu um tempo com procedimentos normatizados por uma prerrogativa atenta somente para as doenças que se apresentam solucionáveis de maneira imediata, e que são pautadas num cuidado do corpo biológico em padecimento, descolado do sujeito? Novamente, um dos entrevistados nos aponta uma pista quando relata: "Esses [usuários] que são predominantemente psiquiátricos, a equipe da emergência não acolhe. Porque esse tipo de paciente você precisa ter uma estrutura para atendê-los, um espaço diferenciado para escutar eles. A internação psiquiátrica é mais complexa que as outras. As pessoas não têm tolerância para fazer o cuidado. A maioria, quarenta por cento dos usuários de emergência têm transtornos 
psiquiátricos menores, mas passam despercebidos, pois os clínicos não têm tolerância para isso" (sic).

Tratar-se-ia da necessidade de estruturas diferenciadas? Seria mesmo uma questão de tolerância?

Nesses termos, o contato com os trabalhadores nas emergências lançou foco na habilidade e disponibilidade para escuta. Muitos deles relataram não somente a ausência de disponibilidade, mas também a sensação de despreparo para o atendimento de casos que envolvessem situações de crises em saúde mental. A esse respeito, através dos relatos, foi percebida a dificuldade que alguns trabalhadores têm em reconhecer não somente que possuem habilidade como também que realizam a escuta dos sujeitos em sofrimento que ali chegam. Supomos que a falta desse reconhecimento se dê em função do não-fechamento, da circulação do sintoma.

Talvez, a sensação, freqüentemente manifestada, de que eles não estão habilitados para o acolhimento desses casos, esteja relacionada ao fato de que situações de crise fazem vazar toda a multiplicidade da vida. Ou seja, tornam visíveis as forças constituintes da existência e nos interpelam de modo perturbador, colocando-nos diante da radicalidade dos encontros com $\mathrm{o}$ instituído no mesmo instante em que estamos sendo atravessados por fluxos instituintes.

Seria essa dimensão que estaria desfocada, embaçada, forjada invisível e de algum modo impedida de ser acolhida, quando são impostas as necessidades de tempo, habilidade, estruturas diferenciadas e tolerância para que se possa realizar o atendimento da crise em saúde mental nas emergências?

Enfim, como realizar um acolhimento em saúde mental dentro de uma emergência geral que não necessite de um fechamento? Diante desse panorama que se apresenta, como produzir diferentes sentidos de acolhimento que lancem foco sob a dimensão de invisibilidade do sofrimento psíquico do sujeito que chega à emergência e que apesar de invisível, ou invisibilizado, circula? Como desviar de uma produção industrial de procedimentos que venham a dar conta de maneira imediata dos sofrimentos psíquicos que afetam grande parte da população? Perguntas por certo sem respostas, mas que têm a intenção de fazer circular o sintoma da invisibilidade do sofrimento psíquico dentro das emergências.

Certamente, a problematização do atendimento à crise só é possível no 
contexto atual graças aos avanços conseguidos pelo movimento de reforma do modelo assistencial em saúde mental. É somente em um contexto de modificação do modelo de assistência, de desospitalização psiquiátrica, de desinstitucionalização da loucura, de reconhecimento do território e das condições de vida como produtoras de saúde, de tentativas diversas de integrar pessoas antes excluídas de qualquer direito de cidadania, que se torna possível interrogar os modos como se tem processado o tratamento oferecido às pessoas em crise. E é preciso avançar, já que os longos anos manicomiais ainda impregnam os serviços de saúde em seus modos de operar o cuidado, sobretudo, na formação de profissionais ainda sustentadas por uma lógica de especialismos que reforça a cultura hospitalocêntrica.

Por fim, em meio ao processo investigativo, através da experimentação do campo que possibilitou o contato com os trabalhadores e suas vivências na emergência, é preciso não perder de vista, como assinala Passos (2012), que não se trata de classificar trabalhadores de humanos ou desumanos, de identificar quais são os serviços humanizados ou desumanizados. O que percebemos são condições propícias ou não para a experimentação de uma função, qualquer que seja sua zona de circunscrição, seja ela a do acolhimento na emergência de um hospital geral, seja ela numa unidade básica de saúde. Isto é, não são os sujeitos que são inábeis e sim as condições que são inadequadas para a instauração de uma nova cultura. Não se trata de uma questão individual, mas de um problema coletivo que, como tal, também só pode encontrar soluções no plano do coletivo.

Nesse sentido, para enfrentarmos o desafio de qualificação da assistência, precisamos tanto entender quais as lógicas presentes nos serviços de saúde e como elas produzem determinados modos de atenção aos usuários, quanto investir em estratégias de formação que operem como ferramentas para a efetivação dos movimentos de mudança desejados. Afinal, parece que não só a doença tem o que dizer, mas o doente, na verdade, tem o que dizer. E aqueles que escutam o doente, trabalham com o doente, parecem ter muito o que dizer sobre o que emerge desse encontro que faz das emergências lugares de salvar vidas - sempre rigorosamente particulares. 


\section{Notas}

${ }^{1}$ Este texto é inédito e sem conflitos de interesse, ele é composto por pesquisadores do "Grupo INTERVIRES: pesquisa-intervenção em políticas públicas, saúde mental e cuidado em rede" vinculado ao Programa de Pós-Graduação em Psicologia Social e Institucional da Universidade Federal do Rio Grande do Sul (UFRGS). O projeto de pesquisa que embasa o artigo possui financiamento do CNPq e foi aprovado nos comitês de ética da UFRGS e do Grupo Hospitalar Conceição.

2 A expressão "crise em saúde mental", ainda que conceitualmente problemática, é aqui utilizada a fim de demarcar uma diferença em relação a um entendimento naturalizado de que as questões referentes à experiência de desorganização subjetiva de um indivíduo pertencem exclusivamente ao campo dos saberes médico-psiquiátricos. Mesmo compreendendo que experiências de crise e rupturas com o instituído integram o processo de saúde que não se faz na oposição, mas na composição com a doença, optamos por utilizar a expressão para demarcar uma contraposição à noção corriqueira de "crise psiquiátrica" - um momento de agudização da sintomatologia de um quadro psiquiátrico gerador de risco para aquele que apresenta tais sintomas. A crise em saúde mental, como aqui a entendemos, seria um momento de intensa fragilidade e sofrimento para um indivíduo, no qual os sentidos construídos já não são suficientes para manejar a realidade e ainda não existem outros de que ele possa lançar mão como estratégia subjetiva exitosa.

3 Ao longo do artigo, os excertos das entrevistas estarão sempre entre aspas, em itálico, seguidos de "segundo informação colhida" (sic).

${ }^{4}$ Alusão ao filme "Fale com ela" de Pedro Almodóvar, 2002.

\section{Referências}

Brasil (2001). Lei $n^{o} 10.216$ de 6 de abril de 2001. Disponível em http://www.planalto.gov.br/ccivil_03 /leis/leis_2001/110216.htm

Brasil (2002). Portaria 2048/ GM de 5 de novembro de 2002. Disponível em http://dtr2001.saude.gov.br/sas/portar ias/port2002/gm/gm-2048.htm

Brasil (2009). Ministério da saúde. Secretaria de atenção à saúde. Política nacional de humanização da atenção e gestão do sus. Acolhimento e classificação de risco nos serviços 
de urgência. Brasília: Ministério da Saúde.

São Paulo. (1995). Resolução $n^{\circ}$ 1451/95 publicada no diário oficial da união em 17.03.1995 - seção i - página 3666.

Cunha, G. T. (2007). A construção da clínica ampliada na atenção básica. São Paulo: Hucitec.

Ferigato, S. H.; Campos, R. O. \& Ballarin, M. L. G. S. (2007). O atendimento à crise em saúde mental: ampliando conceitos. Revista de Psicologia da Unesp, 6(1), p. 31-44.

Fernandes, F. E.; Ramos, S. M.; Frustockl, L. \& França, L. Adaptação do sistema de triagem da emergency severity system. v.4, sd.

Fortes, H. M. (2010). O tratamento compulsório e internações psiquiátricas. Revista Brasileira de Saúde Materno Infantil, Recife, 10 (supl.2): s321-s330 dez.

Foucault, M. Os anormais. (2010). São Paulo: Martins Fontes.

Jardim, K. \& Dimenstein, M. (2007). Risco e crise: pensando os pilares da urgência psiquiátrica. Psicologia em Revista. Belo Horizonte, v. 13, n. 1 , jun.

Lancetti, A. \& Amarante, P. (2006). Saúde mental e saúde coletiva. In G. W. S.
Campos et al. Tratado de Saúde Coletiva. (pp. 615-634). São Paulo: Hucitec; Rio de Janeiro: Ed. Fiocruz. Lipsky, M. (2010). Street-level bureaucracy. Dilemmas of the individual in public services. Russel Sage Foundation: New York.

Luccia, T. P. B. \& Luccia, D. P. B. (2011). $\mathrm{O}$ atendimento da crise psicogênica nos prontos-socorros. Revista Brasileira de Educação Médica, Rio de Janeiro, 35(4).

Mackaway, J. K.; Marsden, J. \& Windle, J. (2006). Emergency triage: manchester triage group. (2 ed). Paperback.

Merhy, E. E. (2007). Em busca do tempo perdido: a micropolítica do trabalho vivo em saúde. In Merhy, E. \& Campos, R. O. Agir em saúde: um desafio para o público. (3a Ed, pp. 71-112). São Paulo: Hucitec.

Merhy, E. E. (2002). Saúde: a cartografia do trabalho vivo. São Paulo: Hucitec.

Neves, C. A. B. \& Heckert, A. L. C. (2010). Micropolítica do processo de acolhimento em saúde. Estudos e pesquisas em psicologia, Uerj, Rio de Janeiro, 10(1), 151-168.

Neves, C. A. B. (2006). Urgências e emergências em saúde: perspectivas de profissionais e usuários. Cadernos 
de Saúde Pública. Rio de Janeiro, 22(3).

Passos, E. (2012). Palestra proferida no II Encontro Estadual de Humanização, realizado em Porto Alegre/RS, em 17 de agosto de 2012.

Ribeiro, Y. C. N. M. B. \& Castro, R. L. V. (2012). Acolhimento com classificação de risco: dois momentos de reflexão em torno das cores. In Brasil, Ministério da Saúde. Cadernos HumanizaSUS, volume 3, Atenção Hospitalar.

Rilke, R. M. (2008). Os cadernos de malte laurides brigge. Osasco, SP: Novo Século Editora.

Sterian, A. (2000). Emergências psiquiátricas. São Paulo: Casa do Psicólogo.

Simone Manieri Paulon: Psicóloga, dra. Em psicologia clínica (pucsp) e docente do ppg de psicologia social da ufrgs, coordenadora do grupo intervires: pesquisa-intervenção em políticas públicas, saúde mental e cuidado em rede.

E-mail: simone.paulon@ufrgs.br

Alice Grasiela Cardoso Rezende Chaves: Psicóloga e mestranda em psicologia social e institucional (ufrgs). E-mail: alicegrasiela@hotmail.com
André Luis Sales Leite: Psicólogo na sesrs, especialista em saúde da família e comunidade / residência integrada em saúde (ghc), mestre em psicologia social e institucional (ufrgs).

E-mail: andreluislfs@ gmail.com

Cássio Streb Nogueira é psicólogo no município de tramandaí, mestrando em psicologia social e institucional - ufrgs. E-mail: cassio_nogueira@yahoo.com.br

Diego Drescher de Castro é acadêmico de psicologia ufrgs, bolsista de iniciação científica pibic cnpq-ufrgs.

E-mail: diegodrescher89@gmail.com

Liana Cristina Della Vecchia Pereira é psicóloga, especialista em saúde da família e comunidade / residência integrada em saúde (ghc).

E-mail: liana.della.vecchia@gmail.com

Mário Francis Petry Londero: Psicólogo, mestre em Psicologia Social e Institucional (UFRGS) e docente no curso de psicologia da UNIVATES (Lajeado/RS).

E-mail: francislonder@hotmail.com

Renata Flores Trepte é acadêmica de psicologia ufrgs, bolsista de iniciação científica pibic cnpq-ufrgs.

E-mail: renata.trepte@gmail.com 